\title{
Outcomes of the infant Ross procedure for congenital aortic stenosis followed into adolescence
}

\author{
Robert W. Elder, MD, ${ }^{\mathrm{a}}$ Jan M. Quaegebeur, MD, PhD, ${ }^{\mathrm{b}}$ Emile A. Bacha, MD, ${ }^{\mathrm{b}}$ Jonathan M. Chen, MD, \\ Francois Bourlon, MD, ${ }^{\mathrm{c}}$ and Ismee A. Williams, MD, $\mathrm{MS}^{\mathrm{a}}$
}

\begin{abstract}
Objectives: The Ross procedure is used to treat aortic valve disease in children. The advantages include autograft growth, long-term durability, and avoidance of anticoagulation. Long-term follow-up of the Ross procedure in infancy is limited. We sought to characterize the long-term outcomes of infants undergoing the Ross procedure.
\end{abstract}

\begin{abstract}
Methods: We performed a retrospective review of all patients who underwent a Ross operation at 18 months of age or younger at New-York Presbyterian and Cardiothoracic Center of Monaco from 1991 to 2010. The clinical, catheterization, and surgical records were reviewed. The most recent follow-up information, including echocardiogram and electrocardiogram, was obtained and analyzed.
\end{abstract}

Results: A total of 34 patients underwent a Ross procedure at a median age of 6 months (range, 4 days to 18.4 months). All had congenital aortic stenosis. All but 1 patient had undergone previous surgical or catheter-based interventions. The median follow-up was 10.6 years (range, 1.4-20.4 years). There were 4 early deaths and 1 late transplant. The freedom from right ventricular outflow tract reintervention was $85 \%$ at 5 years and $64 \%$ at 10 years. The freedom from autograft reintervention was $95.5 \%$ at 10 years. In 20 subjects, late follow-up echocardiograms showed a significant difference between the mean early and late $\mathrm{Z}$ scores of the autograft annulus ( 0.8 vs $2.4, P=.03$ ), sinus ( 0.8 vs $2.8, P=.002)$, and sinotubular junction ( 1.2 vs $2.7, P=.04$ ). Mild or less aortic insufficiency occurred in 17 subjects. None had significant aortic stenosis.

Conclusions: The long-term outcomes of the Ross procedure in infants and toddlers are favorable despite moderate dilatation of the autograft. Reintervention at the right ventricular outflow tract is common. (J Thorac Cardiovasc Surg 2013;145:1504-11)

The Ross procedure uses the native pulmonary valve as an autograft to replace a diseased aortic valve. ${ }^{1}$ Although some critics consider the procedure controversial in that it places 2 valves at risk of future surgical intervention, it has a number of advantages, including the potential for autograft growth, long-term durability, and avoidance of anticoagulation. ${ }^{2}$

Although experience in the adult population is well described, experience in the pediatric population is more

From the Division of Pediatric Cardiology, ${ }^{\mathrm{a}}$ Department of Pediatrics, and Division of Cardiothoracic Surgery, ${ }^{b}$ Columbia University College of Physicians and Surgeons, Morgan Stanley Children's Hospital of New York-Presbyterian, New York, NY; and Division of Pediatric Cardiology, ${ }^{\mathrm{c}}$ Cardiothoracic Center of Monaco, Monaco.

Dr Williams received support from the National Institute of Child Health and Human Development, National Institutes of Health (grant 1K23HD061601). The contents of this report are solely the responsibility of the authors and do not necessarily represent the official views of the National Institute of Child Health and Human Development or the National Institutes of Health.

Disclosures: Authors have nothing to disclose with regard to commercial support.

Received for publication May 18, 2012; revisions received July 24, 2012; accepted for publication Sept 12, 2012; available ahead of print Oct 15, 2012.

Address for reprints: Robert W. Elder, MD, Division of Pediatric Cardiology, Department of Pediatrics, Columbia University College of Physicians and Surgeons, Morgan Stanley Children's Hospital of New York-Presbyterian, 3959 Broadway, 2 North, New York, NY 10032-3784 (E-mail: robelder4@mac.com).

0022-5223/\$36.00

Copyright $(C) 2013$ by The American Association for Thoracic Surgery

http://dx.doi.org/10.1016/j.jtcvs.2012.09.004 limited. In particular, infants who undergo a Ross procedure might represent a distinct subgroup and could have different long-term outcomes, given the relative plasticity of the pulmonary valve at that age. Most infants and toddlers who undergo a Ross procedure have aortic stenosis (AS), and some have multiple levels of left-sided obstructive disease. Most infants who require the procedure have undergone previous interventions, and many are critically ill at surgery. Unlike adult candidates, young patients rarely have isolated aortic insufficiency (AI).

Two reports have been published that address the midterm outcomes of infants who have undergone a Ross procedure. $^{3,4}$ The first study by Williams and colleagues ${ }^{3}$ was published in 2005 and examined the outcomes of 27 infants and toddlers. There were 3 early and no late deaths. At a median follow-up of 6 years, the autograft showed good function despite moderate dilation. ${ }^{3}$ More recently, Shinkawa and colleagues ${ }^{4}$ published follow-up data from 31 infants who had undergone an early Ross at younger than 12 months of age. At a median follow-up of 6 years, survival was $76 \%$ and freedom from reoperation at 10 years was $50.6 \%{ }^{4}$

The purpose of the present study was to examine a large cohort of infant and toddler Ross patients and significantly extend the duration of follow-up for the group into late adolescence. In using the original cohort of patients from the 


$$
\begin{aligned}
& \text { Abbreviations and Acronyms } \\
& \qquad \begin{array}{l}
\text { AI }=\text { aortic insufficiency } \\
\text { AS }=\text { aortic stenosis } \\
\text { BAV } \\
\text { CHB }=\text { balloon aortic valvuloplasty } \\
\text { EFE }=\text { endocte heart block } \\
\text { LVOT }=\text { left ventricular outflow tract } \\
\text { RCA }=\text { right coronary artery } \\
\text { RVOT }=\text { right ventricular outflow tract } \\
\text { STJ }=\text { sinotubular junction }
\end{array}
\end{aligned}
$$

2005 report, ${ }^{3}$ we aimed to provide a long-term assessment of the survival, need for reintervention, and function of the autograft, including the degree of dilatation over time.

\section{METHODS}

\section{Study Design}

All patients who underwent a Ross operation at 18 months of age or younger at Children's Hospital of New-York Presbyterian and the Cardiothoracic Center of Monaco from May 1991 to June 2010 were included. The institutional review board of each institution approved the study and waived informed consent. The medical and surgical records were reviewed to obtain the preoperative data, including age at surgery, gender, body surface area, indications for the procedure, and previous interventions. Operative data, including surgery type, homograft type, additional procedures, cardiopulmonary bypass time, crossclamp time, and complications were recorded. Follow-up data from all survivors were requested from the primary cardiologist, including vital status, most recent echocardiogram and electrocardiogram (ECG), and the need for reintervention, including surgery and catheterization. The hospital records were reviewed to augment the information from the primary cardiologist.

\section{Surgical Technique}

The surgical technique has been previously described. ${ }^{3}$ In brief, the Ross procedure was performed using the root replacement technique without the aid of rings, pledgets, or other reinforcements. The proximal suture line of the autograft was placed below the level of the native aortic annulus to use the natural support structure of the left ventricular outflow tract (LVOT). When necessary, additional surgical procedures, such as the modified Konno procedure, were included. All patients received antegrade cold blood cardioplegia delivered directly into the coronary arteries, as required, every 30 to 40 minutes. The last dose was infused into the aorta after completion of the aortic root reconstruction to assess for bleeding and autograft insufficiency.

\section{ECG Analysis}

All available ECGs were analyzed by a single cardiologist (R.W.E.). The QRS duration was measured and considered to indicate incomplete bundle branch block if greater than the 98th percentile for age ${ }^{5}$ and complete bundle branch block if the QRS duration was longer than $120 \mathrm{~ms}$. When the ECG was not available for review, the primary cardiologist's interpretation was used.

\section{Echocardiographic Analysis}

The echocardiograms from the preoperative period, early postoperative period, and most recent follow-up examination were centrally reviewed by a single cardiologist (I.A.W.). AI, as judged by color Doppler analysis and examination of the descending aortic Doppler flow signal, was graded on a scale of 0 to 4 ( 0 , none; 1 , trivial; 2 , mild; 3 , moderate; and 4 , severe).
Autograft measurements were made off-line in systole at the valve annulus, sinus, and sinotubular junction (STJ); preoperative measurements of the native pulmonary valve were made at the level of the annulus. An average of 3 measurements was used. $\mathrm{Z}$ scores of the autograft were calculated according to the expected norms for the aortic dimensions for body surface area. ${ }^{6}$ Continuous wave Doppler analysis of the LVOT and right ventricular (RV) outflow tract (RVOT) were reviewed, and the peak instantaneous velocity was recorded.

\section{Statistical Analysis}

Continuous variables are reported as the mean \pm standard deviation and categorical values as the count and percentage. Kaplan-Meier estimates of survival and freedom from reintervention were calculated. Z scores from the early postoperative and most recent echocardiograms were compared using the paired Student $t$ test. An $\alpha$-value of $<.05$ was considered significant for all analyses, except in the case of multiple comparisons, in which the Bonferroni correction method was used.

\section{RESULTS}

\section{Patient Characteristics}

From May 1991 to June 2010, we identified 34 patients who had undergone a Ross procedure at 18 months of age or younger, 27 from the original cohort ${ }^{3}$ and 7 since 2004 (Table 1). Most $(\mathrm{n}=27,79 \%)$ had undergone surgery at the Children's Hospital of New York and 7 had undergone surgery at the Cardiothoracic Center of Monaco. The median age at the Ross procedure was 6 months (range, 4 days to 18.4 months); 26 (76.5\%) were boys. All the patients had a primary diagnosis of congenital AS, 12 of whom had isolated valvar AS. The remaining 22 patients had complex left-sided obstructive lesions with associated subvalvar AS $(\mathrm{n}=15)$, supravalvar AS $(\mathrm{n}=2)$, mitral stenosis $(n=3)$, endocardial fibroelastosis (EFE, $n=6)$, coarctation $(\mathrm{n}=8)$, and interrupted aortic $\operatorname{arch}(\mathrm{n}=2)$.

All but 1 patient had undergone an intervention before the Ross procedure. Catheter-based balloon aortic valvuloplasty (BAV) occurred in 22 patients, 9 had undergone surgical valvotomy, and 11 had undergone previous surgical repair of associated lesions, such as coarctation or interrupted aortic arch.

\section{Preoperative Echocardiographic Assessment}

In a subset of 20 patients for whom the immediate preRoss echocardiogram was available, the pulmonary and aortic root size was measured. The pulmonary annulus was, on average, 1.6 times larger than the aortic annulus. Compared with normative values, the mean $\mathrm{Z}$ score for the pulmonary annulus was $0.38 \pm 1.2$, and the mean $\mathrm{Z}$ score for the aortic annulus was $-1.93 \pm 1.5$.

\section{Operative Course}

At the Ross operation, 26 of the 34 patients underwent a Konno modification either to relieve subaortic obstruction or because of the small size of the aortic annulus. Additional concurrent surgical procedures included mitral valvuloplasty in 6, EFE resection in 4, ventricular septal defect repair in 2, 
TABLE 1. Patient characteristics

\begin{tabular}{|c|c|c|c|c|c|c|c|c|c|c|}
\hline \multirow[b]{2}{*}{ Pt. no. } & \multirow{2}{*}{$\begin{array}{c}\text { Previous } \\
\text { balloon } \\
\text { valvuloplasty }\end{array}$} & \multirow{2}{*}{$\begin{array}{c}\text { Previous } \\
\text { surgical } \\
\text { intervention }\end{array}$} & \multirow{2}{*}{$\begin{array}{c}\text { Primary } \\
\text { indication } \\
\text { for Ross } \\
\end{array}$} & \multirow[b]{2}{*}{$\begin{array}{c}\text { Age at } \\
\text { Ross (d) }\end{array}$} & \multirow{2}{*}{$\begin{array}{c}\text { Weight at } \\
\text { surgery } \\
(\mathrm{kg})\end{array}$} & \multirow[b]{2}{*}{ Konno } & \multicolumn{2}{|c|}{ RVOT conduit } & \multirow[b]{2}{*}{ Vital status } & \multirow[b]{2}{*}{$\begin{array}{c}\text { Follow-up } \\
(y)\end{array}$} \\
\hline & & & & & & & Type & $\begin{array}{c}\text { Size } \\
(\mathbf{m m})\end{array}$ & & \\
\hline 1 & No & $\mathrm{CoA}$ & AS/AI & 171 & 7.9 & Yes & Ao & 15 & Alive & 10.8 \\
\hline 2 & Yes & None & AI & 36 & 3 & Yes & Ao & 9.5 & Died & NA \\
\hline 3 & Yes & None & AS/AI & 516 & 8.6 & No & Ao & 17 & Alive & 16.1 \\
\hline 4 & Yes & $\mathrm{CoA}$ & AS/AI & 246 & 5.7 & Yes & $\mathrm{PH}$ & 20 & Alive & 1.4 \\
\hline 5 & No & $\mathrm{CoA}$ & AS & 71 & 9.2 & Yes & Ao & 15 & Alive & 8.5 \\
\hline 6 & Yes & None & AS/AI & 234 & 8 & Yes & $\mathrm{PH}$ & 14.5 & Alive & 10.0 \\
\hline 7 & Yes & None & AS & 122 & 4 & Yes & $\mathrm{PH}$ & 11 & Alive & 10.5 \\
\hline 8 & No & None & AS & 382 & 8.3 & No & PH & 15.5 & Alive & 9.5 \\
\hline 9 & Yes & None & AS/AI & 14 & 3.2 & Yes & $\mathrm{PH}$ & 11 & Transplant & 15.2 \\
\hline 10 & Yes & None & AS/AI & 4 & 2.9 & Yes & $\mathrm{PH}$ & 8 & Alive & 2.5 \\
\hline 11 & Yes & None & $\mathrm{AI}$ & 28 & 3.2 & Yes & Porcine & 14 & Alive & 13.1 \\
\hline 12 & No & SVal & $\mathrm{AI}$ & 273 & 8 & Yes & $\mathrm{PH}$ & 16 & Alive & 12.0 \\
\hline 13 & Yes & $\mathrm{CoA}$ & AS/AI & 14 & 3.6 & Yes & PH & 9 & Died & NA \\
\hline 14 & No & SVal/CoA & AS/AI & 51 & 4.5 & Yes & $\mathrm{PH}$ & 16 & Alive* & 0.0 \\
\hline 15 & Yes & None & AS/AI & 55 & 5.5 & Yes & $\mathrm{PH}$ & 15 & Alive & 8.2 \\
\hline 16 & No & SVal & AS & 102 & 4.7 & No & PH & 15 & Alive & 18.8 \\
\hline 17 & No & $\begin{array}{l}\text { 1: IAA-R, PAB, } \\
\text { sub-AS-R } \\
\text { 2: VSDR, PAB-R }\end{array}$ & AS & 175 & 4.3 & Yes & $\mathrm{PH}$ & 20 & Died & NA \\
\hline 18 & Yes & None & AS/AI & 46 & 3.6 & Yes & Porcine & 14.5 & Alive & 13.9 \\
\hline 19 & Yes & None & AS/AI & 368 & 8.7 & Yes & Ao & 16 & Alive* & 0.0 \\
\hline 20 & No & SVal & AS & 250 & 8 & No & $\mathrm{PH}$ & 15 & Alive & 20.4 \\
\hline 21 & Yes & None & AS/AI & 105 & 4.9 & Yes & $\mathrm{PH}$ & 10 & Alive & 4.7 \\
\hline 22 & No & SVal & AS & 77 & 4.8 & Yes & $\mathrm{PH}$ & 16 & Alive & 17.7 \\
\hline 23 & No & $\mathrm{CoA}$ & AS/AI & 186 & 3.5 & Yes & $\mathrm{PH}$ & 17 & Alive & 6.5 \\
\hline 24 & Yes & None & AS & 421 & 5.6 & No & $\mathrm{PH}$ & 17 & Alive & 5.2 \\
\hline 25 & Yes & None & $\mathrm{AI}$ & 406 & 9.5 & Yes & Ao & 17 & Alive & 15.0 \\
\hline 26 & No & IAA-R, VSDR & AS & 281 & 5.6 & Yes & $\mathrm{PH}$ & 14 & Alive & 6.9 \\
\hline 27 & Yes & SVal & AS & 19 & 3.2 & Yes & Ao & 15 & Alive & 13.8 \\
\hline 28 & Yes & $\begin{array}{l}\text { CoA (arch), SVal, } \\
\text { VSDR }\end{array}$ & AS & 450 & 7.5 & Yes & Ao & 15 & Died & NA \\
\hline 29 & Yes & $\mathrm{CoA}$ & AS/AI & 471 & 11.2 & No & $\mathrm{PH}$ & 23 & Alive & 2.8 \\
\hline 30 & Yes & $\mathrm{CoA}$ & AS/AI & 227 & 5 & No & $\mathrm{PH}$ & 16 & Alive & 14.2 \\
\hline 31 & No & SVal & AS/AI & 154 & 3.9 & Yes & Ao & 22 & Alive & 16.1 \\
\hline 32 & Yes & None & AS & 367 & 10 & Yes & Ao & 17 & Alive & 13.7 \\
\hline 33 & Yes & None & AS/AI & 552 & 9.2 & No & $\mathrm{PH}$ & 20 & Alive & 6.5 \\
\hline 34 & Yes & None & AS/AI & 270 & 8.7 & Yes & $\mathrm{PH}$ & 17 & Alive & 8.3 \\
\hline
\end{tabular}

$A S$, Aortic stenosis; $A I$, aortic insufficiency; $A o$, aortic homograft; $C o A$, coarctation repair; $C o A$ ( arch), repair of hypoplastic arch; $I A A-R$, repair of interrupted aortic arch; $N A$, not applicable; $P A$, pulmonary artery; $P A B$, placement of PA band; $P A B-R$, removal of PA band; PH, pulmonary homograft; Porcine, porcine heterograft; $P t$. no., patient number; SVal, surgical valvotomy; sub-AS-R, resection of subaortic stenosis; VSDR, ventricular septal defect repair. *Alive at discharge.

atrial septal defect closure in 2 , and patent ductus arteriousus closure in 2 . The mean cardiopulmonary bypass time was 173 \pm 35 minutes, and the mean aortic crossclamp time was 118 \pm 27 minutes. Replacement of the native pulmonary valve was accomplished using an aortic homograft in 10 patients, a pulmonary homograft in 22 patients, and a porcine heterograft in 2 patients. The mean size of the homograft placed at the Ross procedure was $15 \pm 3.4 \mathrm{~mm}$.

\section{Mortality}

Of the entire cohort, 4 perioperative deaths occurred, all occurred within the first 24 to 48 hours. A 1-month-old infant, in whom transfer of the right coronary artery (RCA) was technically challenging secondary to a large size discrepancy between the small native aorta and larger pulmonary autograft, died of a right ventricular infarct. A 1-year-old patient developed bilateral pneumothoraces postoperatively, was unable to be resuscitated, and died. A 2-week-old, 3.6-kg infant with a small left ventricle and significant EFE died in the operating room because the left ventricle was unable to support systemic circulation to wean off cardiopulmonary bypass. Finally, a critically ill, 5-month-old infant with complex LVOT obstruction and pulmonary hypertension died after homograft rupture. 
Follow-up information was available for all but 2 of the late survivors, with a median duration from surgery to the latest follow-up examination of 10.6 years (range, 1.420.4 years). The overall survival of the entire cohort at 10 years was $88.2 \%$ (Figure 1 ).

One early survivor (patient 9, Table 1) required a heart transplant 15.2 years after the Ross procedure. This patient had been born with critical AS and EFE and underwent BAV in the immediate neonatal period that resulted in severe aortic valve incompetence. The Ross procedure was performed at 14 days of age. He underwent pulmonary valve replacement 9 years later. At 14 years old, he developed progressive heart failure symptoms. An echocardiogram at that time demonstrated his autograft functioning well with only trivial AI and no significant stenosis. He underwent cardiac transplantation, and pathologic examination of the explanted heart showed an unremarkable autograft with well-endothelilized coronary artery buttons. Histologic examination of the left ventricular myocardium showed focal endocardial thickening, myocyte hypertrophy, and patchy subendocardial fibrosis. No other late deaths or transplantations occurred in the present series.

\section{RVOT Outcomes}

The freedom from any RVOT reintervention at 5, 10, and 15 years was $85 \%, 64 \%$, and 23\%, respectively (Figure 2 ). Surgical replacement of the right ventricle to pulmonary artery (PA) conduit occurred in 9 and catheter-based procedures in 6 . Of these 6 patients, 4 had a stent placed in the RVOT, 1 underwent balloon dilation of the RVOT, and 1

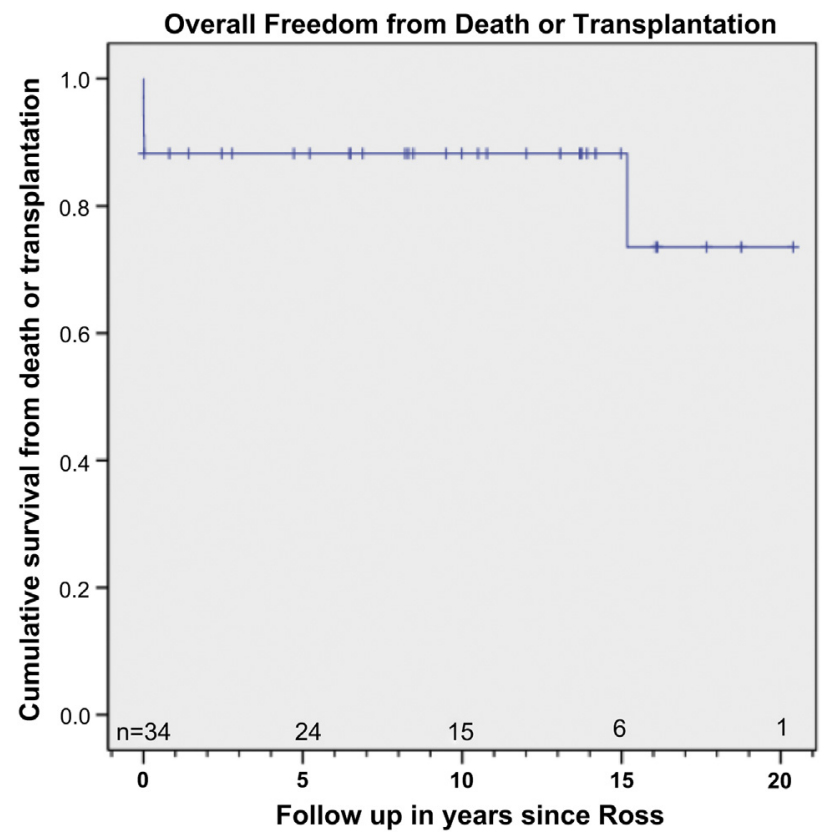

FIGURE 1. Overall freedom from death or transplantation. Number above $\mathrm{x}$-axis indicates number at risk at given period.

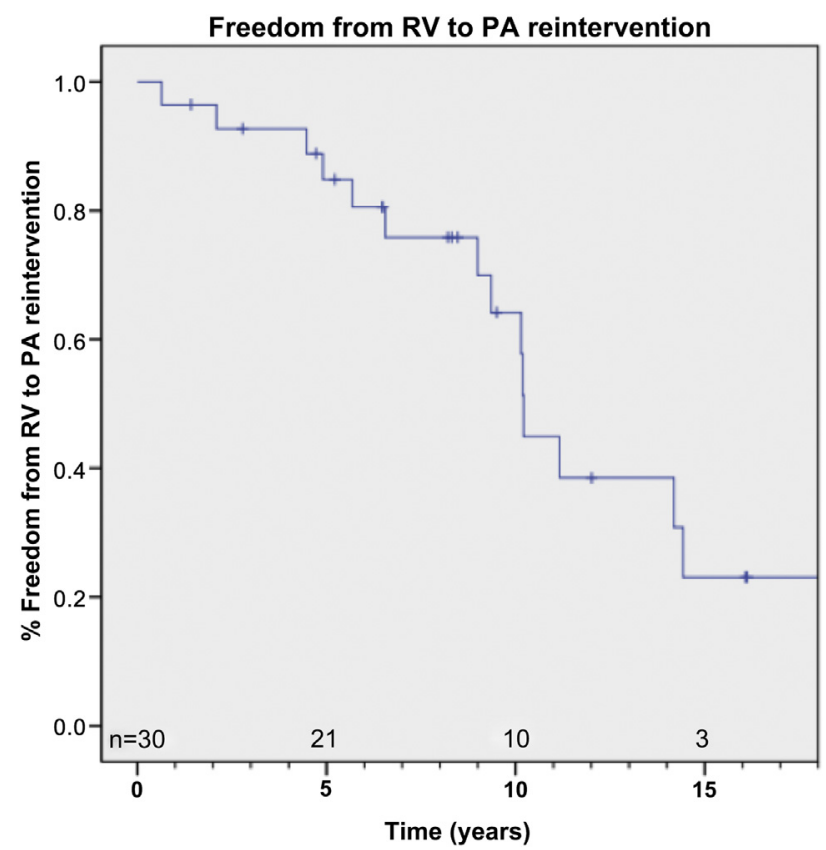

FIGURE 2. Freedom from right ventricular outflow tract reintervention Number above $\mathrm{x}$-axis indicates number at risk at given period. $P A$, Pulmonary artery; $R V$, right ventricle.

underwent placement of a transcutaneous Melody valve for relief of stenosis and regurgitation. Of the 4 patients who had a stent placed in the RVOT, 3 subsequently required surgical replacement of the conduit (1 each 8 months later, 3.5 years later, and nearly 8 years later). At the writing of our report, we were aware of 2 other patients in the series who have been referred for RVOT surgical revision: 1 had previously undergone conduit replacement and 1 has not had any RVOT interventions since the Ross procedure.

\section{Autograft Outcomes}

Of the entire cohort, freedom from autograft reintervention was $95.5 \%$ at 10 years, with only 1 patient requiring reintervention 5.7 years after the Ross procedure (patient 7, Table 1). The patient had AS and sub-AS and had undergone a Ross-Konno procedure at 2 months of age after unsuccessful BAV. He slowly developed progressive subAS associated with significant AI and at 6 years of age underwent surgical repair of his autograft with simultaneous relief of RVOT obstruction. Intraoperatively, the left coronary cusp was elongated with associated prolapse and insufficiency of the valve and significant residual sub-AS. Repair of the valve and resection of the subaortic tissue was undertaken. At the most recent follow-up visit, the patient had moderate $\mathrm{AI}$ and mild $\mathrm{AS}(<20 \mathrm{~mm} \mathrm{Hg})$.

\section{ECG Analysis}

Late-term ECGs were available for 29 of the 30 survivors of the infant Ross procedure. One infant with Shone 
syndrome who had undergone a Ross-Konno procedure at 2 months of age developed operative complete heart block (CHB) requiring a permanent pacemaker. No other CHB was noted among the survivors. Of the 4 early deaths, 1 patient had had CHB, 2 had not had CHB, and 1 patient had no ECG available for review. The other ECG findings in the long-term survivors included sinus bradycardia $(\mathrm{n}=1)$, first-degree heart block $(n=1)$, incomplete $(n=5)$ or complete $(\mathrm{n}=3)$ right bundle branch block, left-anterior hemiblock $(\mathrm{n}=3)$, and left bundle branch block $(\mathrm{n}=1)$.

\section{Echocardiographic Analysis}

Late follow-up echocardiogram measurements were available for 20 subjects $(66 \%)$ at a mean of $10.3 \pm 5.2$ years after the Ross procedure and were compared with the early postoperative echocardiogram measurements obtained at a mean of $11 \pm 8$ days postoperatively. At the latest follow-up examination, the autograft dimension $\mathrm{Z}$ scores were elevated and showed dilatation at all 3 measured levels (Figure 3,A). A significant difference was seen between the mean early and late $\mathrm{Z}$ scores of the autograft annulus $(0.8 \mathrm{vs}$ $2.4, P=.03)$, sinus (0.8 vs $2.8, P=.002)$, and STJ (1.2 vs
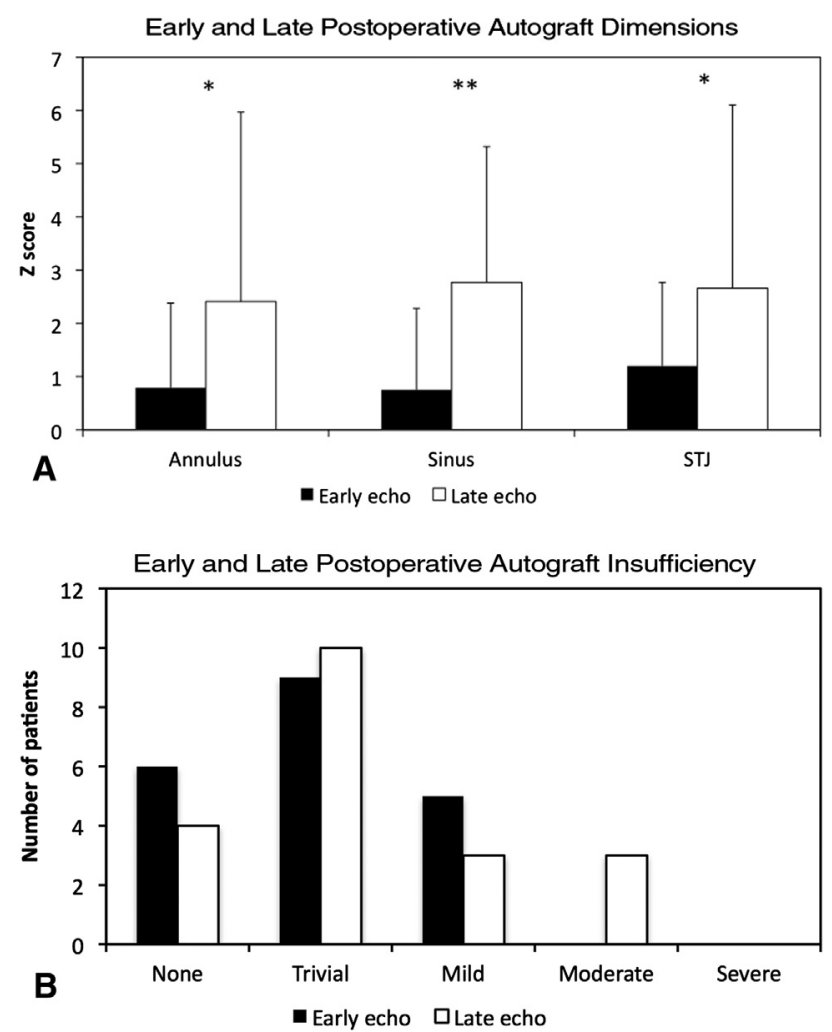

FIGURE 3. Comparison of early postoperative and late echocardiograms (echo) in 20 patients. A, Late echocardiogram showing dilatation ( $\mathrm{Z}$ score $>2$ ) at annulus, sinus, and sinotubular junction (STJ), with statistically significant difference between early and late echocardiogram mean $\mathrm{Z}$ scores. $* P \leq .05, * * P \leq .002$. B, Comparison of aortic insufficiency quantification.
2.7, $P=.04)$. Autograft function remained good in most patients, with AI quantified as mild or less in 17 subjects, mild to moderate in 1 , and moderate in 2 (Figure 3, B). Of the 2 patients with moderate AI, 1 had previously undergone surgical reintervention at the level of the autograft but 5 years after the reintervention continued to have moderate insufficiency. None of the long-term follow-up echocardiograms showed significant AS (> $20 \mathrm{~mm} \mathrm{Hg}$ ).

To address the progression of autograft dilatation over time, serial echocardiograms were examined in a subset of 14 patients at 3 points: early postoperatively (median, 8 days), midterm (median, 4.5 years), and at the latest follow-up visit (median, 11.4 years). When the $\mathrm{Z}$ scores for the early and midterm echocardiograms were compared, significant dilatation had occurred at all 3 levels $(P<.001$; Figure $4, A$ ). When the midterm and late echocardiograms were compared, a trend was seen toward decreased $\mathrm{Z}$ scores at all 3 levels, although only the STJ showed a significantly decreased $\mathrm{Z}$ score $(P=.003$, Figure $4, A)$. Scatter plots of the 14 patients' $Z$ scores over time at the 3 intervals demonstrated variability in the individual response (Figure 4, $B-D$ ).

\section{Associated Interventions and Long-Term Complications}

Two patients required subsequent cardiovascular surgical interventions other than revision of the RVOT or autograft: 1 required resection of a supramitral valve membrane 1.5 years after the Ross procedure and 1 underwent diagnostic catheterization for homograft stenosis 14 years after the Ross procedure and was found to have a previously unrecognized anomalous left upper pulmonary vein draining to the innominate vein that was repaired at the same time as the conduit replacement.

Long-term medical complications developed in 3 patients. One patient with CHB required multiple pacemaker revisions. Streptococcal endocarditis developed in 1 patient 12 years after the Ross procedure and 9 years after right ventricle to PA conduit replacement. A third patient underwent diagnostic cardiac catheterization 11 years after the Ross procedure and was incidentally found to have occlusion of the proximal RCA with collateral filling of the right coronary distribution. The patient was asymptomatic, and a recent nuclear stress test showed no evidence of flow-limited coronary artery disease.

\section{DISCUSSION}

We report the results of a large series of 34 patients, who had undergone a Ross procedure at 18 months of age or younger, with an extended follow-up, nearly doubling the median length of follow-up from the 2 previous largest series. $^{3,4}$ At a median duration of 10.6 years after the Ross operation, all but 1 of the surviving patients in our study remained free from significant autograft disease requiring reintervention. 
Comparison of $Z$ score in early, mid-term, and late echocardiograms

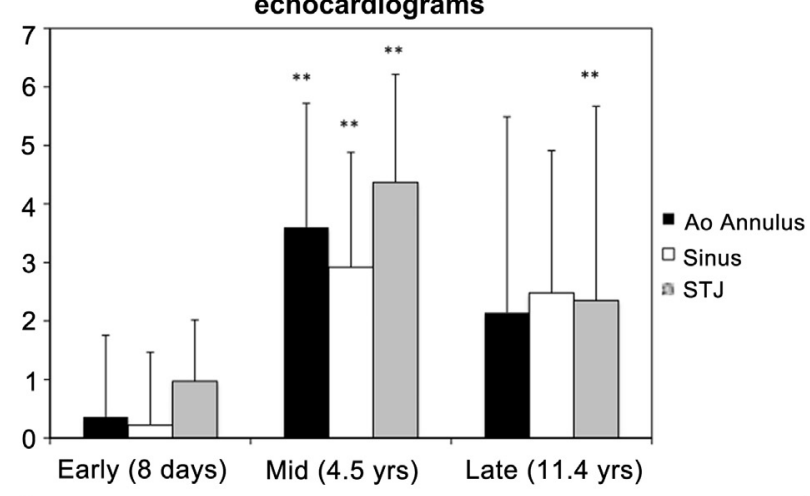

A

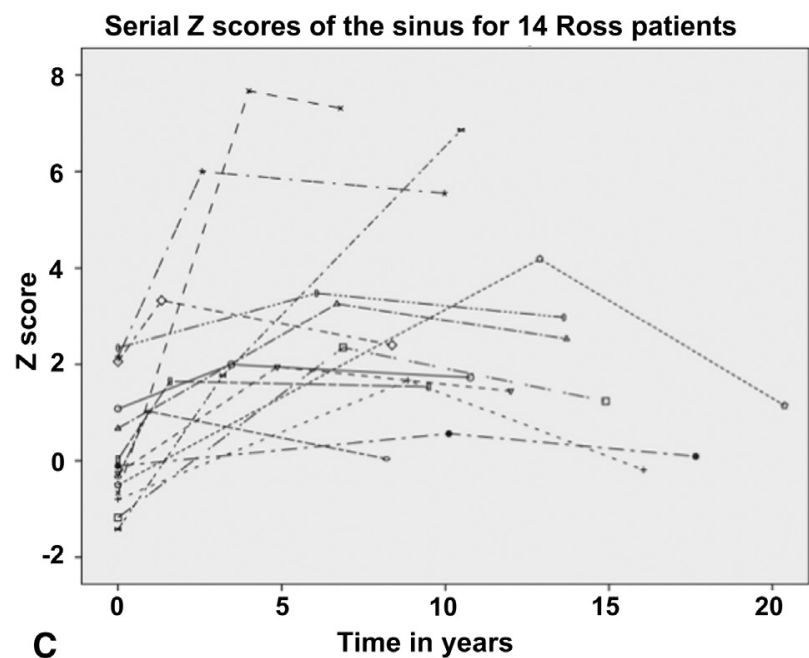

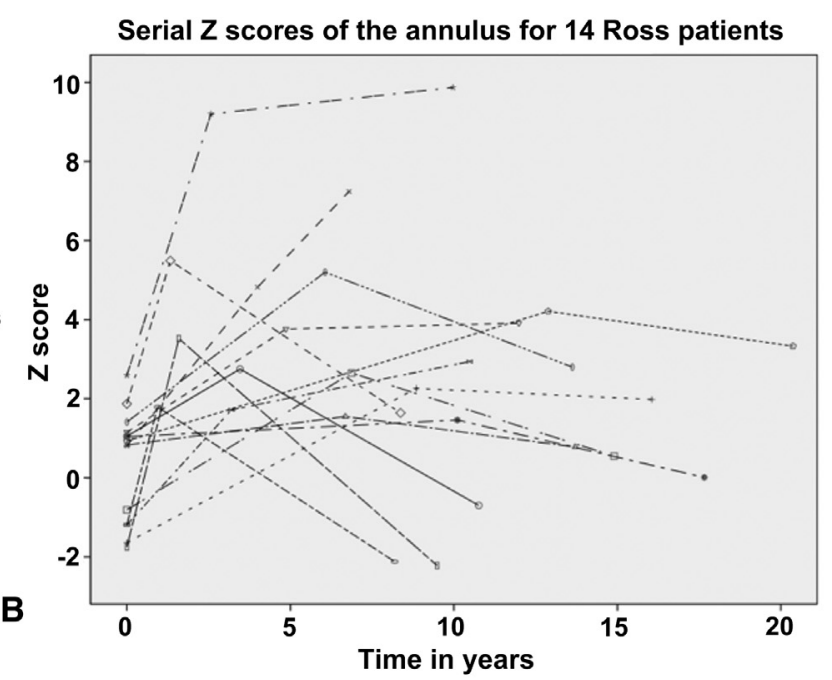

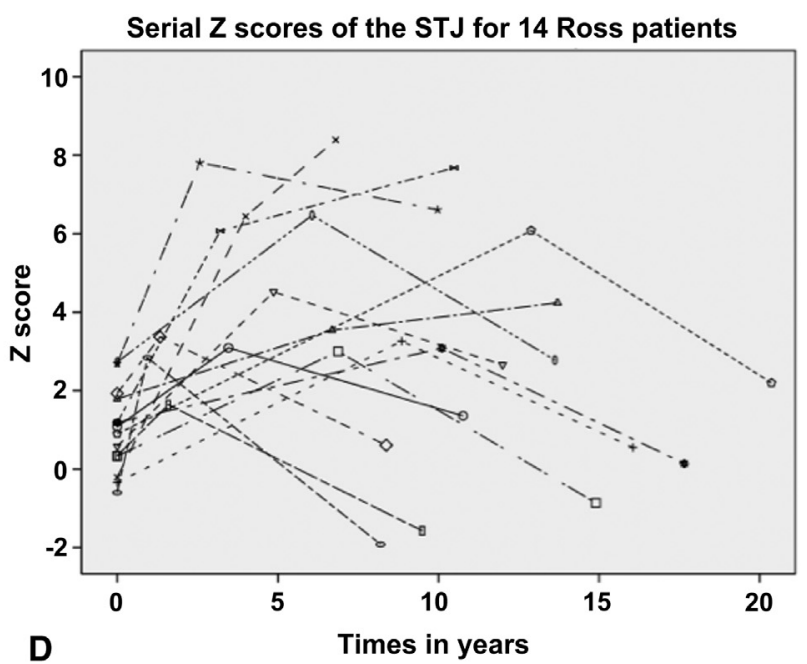

FIGURE 4. Follow-up of serial autograft dilatation in subset of 14 patients. A, Comparison of mean $\mathrm{Z}$ scores at 3 intervals. Individual $\mathrm{Z}$ scores for, B, annulus, $\mathrm{C}$, sinus, and, $\mathrm{D}$, sinotubular junction $(S T J)$ at 3 points. $* * P \leq .003$. Ao, Aortic.

Overall, the infants represented by the present cohort are a critically ill group of patients with limited surgical options at presentation. Although complex aortic valve repair has been described with respectable intermediate-term results, ${ }^{7}$ the technical challenges in the infant makes this a less tenable option. Furthermore, $76 \%$ of our group required a Konno modification to address LVOT obstruction, which would not be addressed by aortic valve repair alone. Most of the patients required initial catheter-based BAV. Some required an urgent Ross procedure for subsequent procedure-related significant AI, a known complication of BAV that occurs in $22 \%$ to $29 \%$ of infants. ${ }^{8,9}$

Despite the challenges of surgery in this young, critically ill, group of patients, the mortality and long-term outcomes were quite favorable compared with both general pediatric $^{10-12}$ and young infant subpopulations of the Ross procedure. $^{4}$ In our group, 4 patients died in the early postoperative period. Of the 4 deaths, $3(75 \%)$ occurred before 2000 and none in the past 10 years. Also, 2 of the 4 deaths occurred in infants 1 month old or younger at the Ross procedure. One death was secondary to a small left ventricle with significant EFE, the other was secondary to the technical challenges of the Ross procedure that relate to transfer of the RCA when a large size discrepancy is present between the larger PA and the smaller aorta. During the study period, with many patients followed up into adolescence, only 1 additional patient with a history of EFE at birth, who underwent the Ross procedure at 14 days of age, ultimately required cardiac transplantation. No late deaths occurred in our series.

Infants, in particular, might be better suited to the Ross procedure. When the semilunar valves of mice were analyzed histochemically, Colvee and Hurle ${ }^{13}$ showed that the collagen and mucopolysaccharide composition of the valves continued to change postnatally. They concluded that "maturation of the valves occurs over a long period of the postnatal life." 13 The microscopic structure of the 
pulmonary valve and root complex might be better able to adapt to the hemodynamic changes of systemic circulation when the Ross procedure is performed in infancy.

\section{Autograft Outcomes}

The neoaortic root did appear to be dilated, with late-term echocardiograms showing $\mathrm{Z}$ scores greater than the norm. In our series, a statistically significant difference was seen between the $\mathrm{Z}$ scores for the autograft dimensions for the annulus, sinus, and STJ at the latest follow-up examination and those from the echocardiograms in the early postoperative period. Solowiejczyk and colleagues ${ }^{14}$ studied a pediatric population of Ross patients and showed progressive dilatation of the autograft over time compared with the normal aortic dimensions. Compared with the $\mathrm{Z}$ scores for a pulmonary trunk, the autograft showed less pronounced dilatation. Others have similarly showed that most pediatric patients have autograft $\mathrm{Z}$ scores outside the norm for the aortic root. ${ }^{10,15}$

In the series of 31 infants reported by Shinkawa and colleagues, ${ }^{4}$ the discharge echocardiograms already showed significant dilatation, with a mean $\mathrm{Z}$ score of the annulus and STJ of 4.3 and 4.0, respectively. When they compared those early values with measurements derived from later echocardiograms (performed at a median of 6 years after Ross), no statistically significant difference was found, suggesting that the timing of the discharge echocardiogram had already captured the dilatation. It is possible that in our study the early postoperative echocardiogram measured at a mean of 11 days was too soon after surgery to show the dilatation, or, perhaps, differences in surgical technique were present between the centers. When we evaluated the serial measurements of the autograft over time in a subpopulation, the dilatation appeared to occur early, with the comparison of the mid and late echocardiograms showing little change or in some cases decreased $\mathrm{Z}$ scores. This suggests that the autograft does not continue to dilate with time but, rather, stabilizes compared with the body surface area in this age group.

Regardless of dilatation, the function of the autograft is of primary importance after a Ross procedure. In our series and others, ${ }^{10-12}$ very few patients have required reintervention of the autograft. The vast majority of patients in the present series had mild or less insufficiency and were asymptomatic at their latest follow-up visit. None of the patients had significant residual AS. We believe that in this particular young group, no other procedure is available that will provide the same hemodynamic advantages.

\section{RVOT Outcomes}

Many critics are concerned because the Ross procedure places 2 valves at risk of future problems. Many of our group did require reintervention of the right ventricle to PA conduit, as expected with associated somatic growth. However, despite their young age at the initial operation,
$64 \%$ had still not required any procedural intervention of the right ventricle to PA conduit at 10 years of follow-up. In this era of advances in percutaneous interventions, it is noteworthy that 6 of the 15 initial interventions were catheter based, including placement of 1 Melody valve. In the future, this group of young Ross patients might be candidates for transcatheter valve therapy, especially as the population ages and might require a second or third right ventricle to PA conduit intervention.

\section{ECG Analysis}

Although the infant subgroup might seem to be at a greater risk of CHB, in our series, only 1 late-term survivor had CHB. Pasquali and colleagues ${ }^{16}$ reported rhythm and conduction disturbances in a pediatric Ross population at a median of 8.7 years postoperatively; $4 \%$ had CHB, a number similar to that in our infant group. This suggests that despite the younger age and smaller size at surgery, in experienced hands, the risk to the conduction system is comparable to that in older patients. In the series by Pasquali and colleagues, ${ }^{16}$ when they analyzed the Holter results, sinus node dysfunction was found in $15 \%$ and another $15 \%$ had ventricular tachycardia. Although Holter studies were not consistently available for our cohort, the late follow-up ECGs showed a number of conduction disturbances that probably warrant Holter monitoring during follow-up.

\section{Surgical Considerations}

One of the technical surgical challenges of the Ross procedure in young infants occurs when a marked size discrepancy is present between the native pulmonary and aortic annuli. In particular, relocation of the RCA button can be challenging, and in 3 patients in our series, the RCA was reimplanted into the noncoronary sinus of the autograft to minimize tension on the RCA. Relocation of the coronary arteries can be associated with morbidity and mortality. One patient in whom the RCA was implanted into the normal, anterior sinus died of an RCA infarct. One survivor, in whom the coronary arteries were also normally reimplanted, was incidentally discovered by catheterization to have RCA occlusion with good collateralization.

\section{Study Limitations}

Our study was limited by its retrospective nature. Of the group of 30 late survivors, 2 patients were lost to follow-up. Also, 8 of the patients with known follow-up data did not have a recent echocardiogram available for analysis. Given that the echocardiograms and ECGs were not consistently available, analysis of subgroups was performed that could have biased the overall findings. Finally, the present study did not address more functional analyses of the patients' status, such as maximal exercise testing, which could be a helpful alternative to understanding subtle differences in functional capacity. 


\section{CONCLUSIONS}

The long-term outcomes of the Ross procedure in infants and toddlers are favorable despite moderate dilatation of the autograft. Reintervention at the RVOT is common.

We gratefully acknowledge the assistance in manuscript editing and thoughtful comments from Dr Thomas Starc and the assistance with conceptualization and realization of this project by Dr David Solowiejczyk.

\section{References}

1. Ross DN. Replacement of aortic and mitral valves with a pulmonary autograft. Lancet. 1967;2:956-8.

2. Al-Halees Z, Pieters F, Qadoura F, Shahid M, Al-Amri M, Al-Fadley F. The Ross procedure is the procedure of choice for congenital aortic valve disease. J Thorac Cardiovasc Surg. 2002;123:437-42.

3. Williams IA, Quaegebeur JM, Hsu DT, Gersony WM, Bourlon F, Mosca RS, et al. Ross procedure in infants and toddlers followed into childhood. Circulation. 2005;112(9 Suppl):I390-5.

4. Shinkawa T, Bove EL, Hirsch JC, Devaney EJ, Ohye RG. Intermediate-term results of the Ross procedure in neonates and infants. Ann Thorac Surg. 2010;89:1827-32.

5. Garson A. The Electrocardiogram in Infants and Children: A Systematic Approach. Philadelphia: Lea \& Febiger; 1983:397.

6. Colan SD, McElhinney DB, Crawford EC, Keane JF, Lock JE. Validation and reevaluation of a discriminant model predicting anatomic suitability for biventricular repair in neonates with aortic stenosis. J Am Coll Cardiol. 2006;47:1858-65.

7. Tweddell JS, Pelech AN, Frommelt PC, Jaquiss RD, Hoffman GM, Mussatto KA, et al. Complex aortic valve repair as a durable and effective alter- native to valve replacement in children with aortic valve disease. J Thorac Cardiovasc Surg. 2005;129:551-8.

8. Fratz S, Gildein HP, Balling G, Sebening W, Genz T, Eicken A, et al. Aortic valvuloplasty in pediatric patients substantially postpones the need for aortic valve surgery: a single-center experience of 188 patients after up to 17.5 years of follow-up. Circulation. 2008;117:1201-6.

9. Reich O, Tax P, Marek J, Razek V, Gilik J, Tomek V, et al. Long term results of percutaneous balloon valvoplasty of congenital aortic stenosis: independent predictors of outcome. Heart. 2004;90:70-6.

10. Piccardo A, Ghez O, Gariboldi V, Riberi A, Collart F, Kreitmann B, et al. Ross and Ross-Konno procedures in infants, children and adolescents: a 13-year experience. J Heart Valve Dis. 2009;18:76-83.

11. Alsoufi B, Al-Halees Z, Manlhiot C, McCrindle BW, Kandeel M, Al-Joufan M, et al. Superior results following the Ross procedure in patients with congenital heart disease. J Heart Valve Dis. 2010;19:269-78.

12. Hraska V, Krajci M, Haun C, Ntalakoura K, Razek V, Lacour-Gayet F, et al. Ross and Ross-Konno procedure in children and adolescents: mid-term results. Eur J Cardiothorac Surg. 2004;25:742-7.

13. Colvee E, Hurle JM. Maturation of the extracellular material of the semilunar heart values in the mouse: a histochemical analysis of collagen and mucopolysaccharides. Anat Embryol (Berl). 1981;162:343-52.

14. Solowiejczyk DE, Bourlon F, Apfel HD, Hordof AJ, Hsu DT, Crabtree G, et al. Serial echocardiographic measurements of the pulmonary autograft in the aortic valve position after the Ross operation in a pediatric population using normal pulmonary artery dimensions as the reference standard. Am J Cardiol. 2000;85:1119-23.

15. Frigiola A, Varrica A, Satriano A, Giamberti A, Pomè G, Abella R, et al. Neoaortic valve and root complex evolution after Ross operation in infants, children, and adolescents. Ann Thorac Surg. 2010;90:1278-85.

16. Pasquali SK, Marino BS, Kaltman JR, Schissler AJ, Wernovsky G, Cohen MS et al. Rhythm and conduction disturbances at midterm follow-up after the Ross procedure in infants, children, and young adults. Ann Thorac Surg. 2008;85:2072-8. 